\title{
Exocervical Carcinoma
}

National Cancer Institute

\section{Source}

National Cancer Institute. Exocervical Carcinoma. NCI Thesaurus. Code C7453.

A carcinoma that arises from the squamous epithelium of the exocervix. 